\title{
Numerical Simulation of Internal Loop Reactor for Heavy Oil Slurry Bed Hydroprocessing
}

\author{
Sun Lanyi*, Wang Jian, Bai Fei and Bo Shoushi
}

State Key Laboratory of Heavy Oil Processing, China University of Petroleum, Qingdao 266580, China

\begin{abstract}
Computational Fluid Dynamics (CFD) simulations of internal loop reactor for heavy oil slurry bed hydroprocessing have been done in commercial code Fluent 6.3 using Euler two-phase flow model and standard $k$ - $\varepsilon$ turbulence model. The effects of the physical properties on the flow field in the reactor are investigated. The results show that the gas density has little effect but the liquid viscosity has a significant effect on flow field and gas hold-up. An analysis of the effect of reactor structures and scale-up on the flow field and gas hold-up are also provided, and optimal structure is obtained through simulations. The conclusions obtained in this paper have great significance for the slurry bed hydrocracking process.
\end{abstract}

Keywords: Heavy oil, internal loop reactor, numerical simulation, slurry bed hydroprocessing.

\section{INTRODUCTION}

It is well accepted that the crude oils available to refineries are becoming heavier. Meanwhile, the demand for high value products such as gasoline and middle distillates is increasing. The trend towards heavy feedstock and urgent demand for high quality products as well as tightening fuel regulations are presenting new challenges for refineries [1-4]. The hydroprocessing of heavy oil is one of the main processes for converting a heavy carbonaceous feedstock to lower-boiling products. Various heavy oil hydroprocessing are now commercially employed using fixed bed, moving bed, ebullated bed and slurry bed $[5,6]$. Among them, the slurry bed process shows its special superiority in treating heavy oil containing large amount of metals, carbon residue and asphaltene. This process as a heavy oil processing technology has several advantages such as a more simple process flow scheme, flexible operation and process reliability, high space velocity and conversion rates, no bed plugging problems and a wider adaptability to different sources of raw materials $[1,7,8]$.

The internal loop reactor has been successfully used in slurry bed hydroprocessing, it possesses good mixing, mass and heat transfer characteristics. The reactor consists of two interconnected main parts, the riser and the downcomer. Gas is injected into the riser and the resulting difference between average densities in the riser and in the downcomer provides a driving force for liquid circulation [9].

Owning to the high investment and limitation of experimental methods, Computational Fluid Dynamics (CFD) are relatively easy to use and robust. The field of applications ranges from simple two-dimensional isothermal

*Address correspondence to this author at the State Key Laboratory of Heavy Oil Processing, China University of Petroleum, Qingdao 266580, Shandong, China; Tel: +86-138-5420-8340; Fax: +86-0532-8698-1787;

E-mail: sunlanyi@163.com flows to complex three-dimensional unsteady flows with combustion. This technique, relying on less expensive but increasingly powerful computers, has been widely used in flow dynamic investigations and reactor design and scale-up in the recent decade. And it is becoming more and more popular with high reliability, especially for reactors operating under high pressure and high temperature. CFD simulation is based on the local solution of the mass and momentum balance equations [10-14]. Then the information on complete flow field inside domain of interest will be obtained [15-17], etc.

In this paper, the CFD simulations of internal loop reactor for heavy oil slurry bed hydroprocessing were done in commercial code Fluent 6.3 using Euler two-phase flow model and standard $k-\varepsilon$ turbulence model [18-20]. The internal flow field and gas hold-up were simulated with different gas and oil properties and bubble diameters in various structures of draft tube and reactor, then optimal structure was obtained. It is expected the present work will be a valuable reference for the design and scale-up of loop reactor used in slurry bed hydrocracking process.

\section{MATHEMATICAL MODEL}

\subsection{Continuity Equation}

The continuity equation is described as following:

$\frac{\partial}{\partial t}\left(\alpha_{q} \rho_{q}\right)+\operatorname{div}\left(\alpha_{q} \rho_{q} u_{q}\right)=m_{p q}$

where $\alpha_{q}, \rho_{q}, u_{q}$ are gas hold-up, density and velocity in each phase, respectively; $m_{p q}$ represents the mass transfer from phase $p$ to phase $q, \mathrm{~kg} / \mathrm{m}^{3} \cdot \mathrm{s}$, which is 0 in this study.

\subsection{Momentum Transfer Equation}

The momentum transfer equation is described as following: 
$\frac{\partial}{\partial t}\left(\alpha_{q} \rho_{q} u_{q}\right)+\operatorname{div}\left(\alpha_{q} \rho_{q} u_{q} u_{q}\right)=-\alpha_{q} \cdot\left(\operatorname{grad} p+\rho_{q} g+\rho_{q} F\right)$

$+\operatorname{div} \overline{\bar{\tau}}+K_{p q}\left(u_{p}-u_{q}\right)+m_{p q} u_{p q}$

where $p$ is the pressure, $\mathrm{Pa} ; \overline{\bar{\tau}}$ is the stress-strain tensor; $F$ is body force; $K$ is momentum transfer coefficient for drag force.

\subsection{Turbulence Equations}

The standard $k-\varepsilon$ model was used to model turbulence. This model belongs to a group of Reynolds averaged NavierStokes equation models. The turbulent kinetic energy $k$ and turbulent dissipation rate $\varepsilon$ are obtained by solving their transport equations:

$$
\begin{aligned}
& \frac{\partial}{\partial t}(\rho k)+\operatorname{div}(\rho u k)=\operatorname{div}\left[\left(\mu+\frac{\mu_{t}}{\sigma_{\kappa}}\right) \operatorname{grad} k\right]-\rho \varepsilon+\mu_{t} P_{k} \\
& \frac{\partial}{\partial t}(\rho \varepsilon)+\operatorname{div}(\rho u \varepsilon)=\operatorname{div}\left[\left(\mu+\frac{\mu_{t}}{\sigma_{\varepsilon}}\right) \operatorname{grad} \varepsilon\right] \\
& -\rho C_{2} \frac{\varepsilon^{2}}{k}+\mu_{t} C_{1} \frac{\varepsilon}{k} P_{k}
\end{aligned}
$$

where $\mu_{t}$ is the turbulence viscosity, which requires a closure equation. The closure is:

$\mu_{t}=\rho C_{\mu} \frac{k^{2}}{\varepsilon}$

the turbulent model constants are:

$$
C_{\mu}=0.09 ; \sigma_{k}=1.0 ; \sigma_{\varepsilon}=1.3 ; C_{1}=1.44 ; C_{2}=1.92 \text {. }
$$

\section{MODEL VALIDATION}

The verifications and validations of the reliability of CFD models in simulation of loop reactor are very important. In order to compare our simulations quantitatively with both available experimental and simulated data, we have chosen to base our investigations on published works of Tsinghua University [9]. Euler two-phase flow model and standard $k-\varepsilon$ turbulence model were selected to carry out the CFD simulations. The airlift dimensions in simulations are the same with Tsinghua University experimental devices. Experimental verification includes the comparison of the liquid circulation velocity and gas hold-up.

The liquid circulation velocity and gas hold-up in the flow field are compared with experimental data at different superficial gas velocity. The riser and downcomer liquid circulation velocities are compared in Fig. (1) and Fig. (2), respectively. Figs. (3-5) show the comparison of gas hold-up at three different locations in the reactor. From the comparison, we find the change trend of simulation results is in line with that of experimental data, however, minor differences have also been displayed between them. Three possible reasons listed below may cause the errors. (1) The distributor of the reactor in the experiment is simplified to a sintered plate. (2) The wall of reactor and tube are regarded as smooth surface. (3) The experimental data may have minor errors.

According to the comparison and published literatures, Euler two-phase flow model and standard $k-\varepsilon$ turbulence model are still adopted to predict the internal flow field and gas hold-up distribution in the loop reactor, ignoring the minor errors.

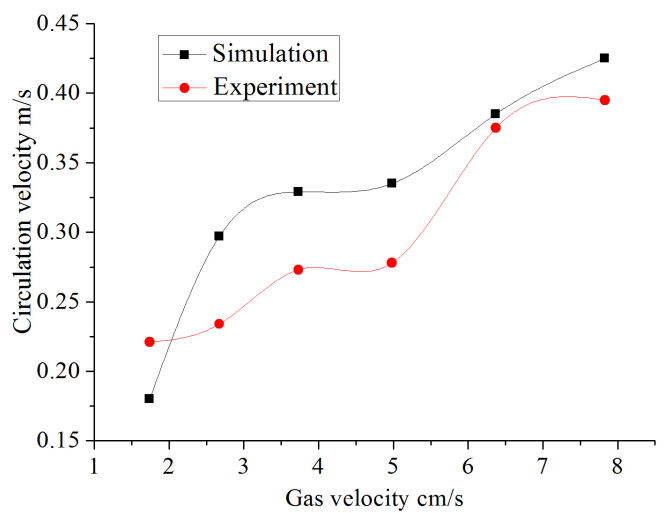

Fig. (1). Riser liquid circulation velocity versus gas velocity.

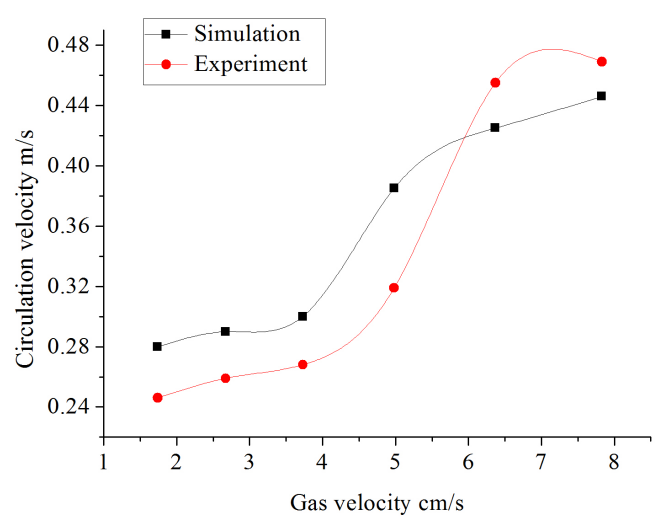

Fig. (2). Downcomer liquid circulation velocity versus gas velocity.

\section{ESTABLISHMENT OF THE MODEL}

The reactor model was established according to the parameters presented in Table 1. And in order to accelerate the calculation in the computer, the two-dimensional loop reactor model with hybrid grid was recommended, as shown in Fig. (6).

The boundary and operating conditions in the simulation are set referring to the $50 \mathrm{kt} / \mathrm{a}$ heavy oil slurry bed hydrocracking process, in which the liquid feed is $9.5 \mathrm{t} / \mathrm{h}$, the volume ratio of hydrogen to oil is 800 [4-6], the high temperature and pressure are $420{ }^{\circ} \mathrm{C}$ and $10 \mathrm{MPa}$, respectively. 
Table 1. Parameters of the reactor.

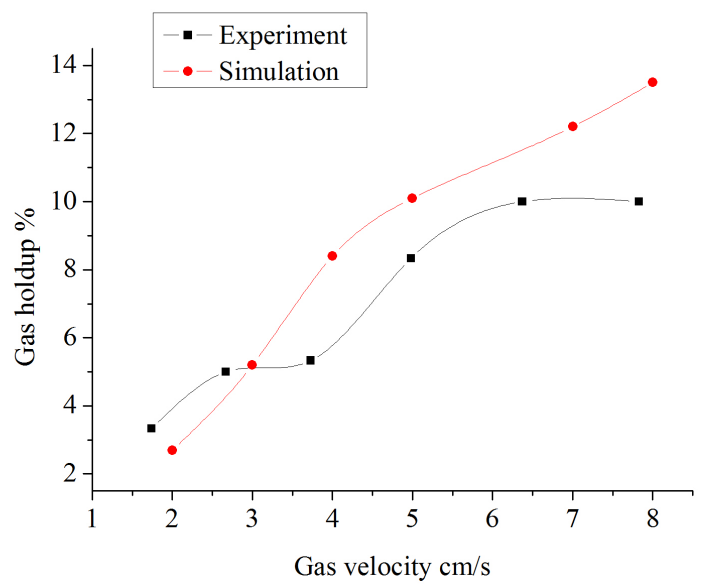

Fig. (3). Gas hold-up with gas velocity at certain height of crosssection $(\mathrm{h}=0.8 \mathrm{~m})$.

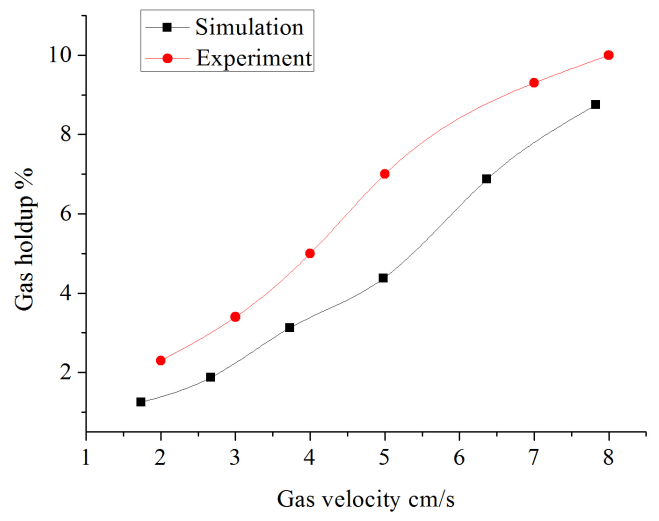

Fig. (4). Gas hold-up with gas velocity at certain height of crosssection $(\mathrm{h}=1.4 \mathrm{~m})$.

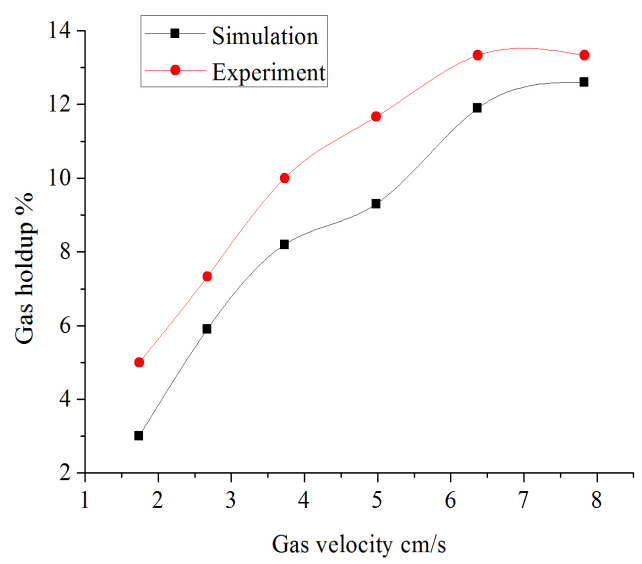

Fig. (5). Gas hold-up with gas velocity at certain height of crosssection $(\mathrm{h}=2.7 \mathrm{~m})$.

\begin{tabular}{|c|c|}
\hline Parameters & Value $/ \mathbf{m}$ \\
\hline \hline Height of reactor & 10 \\
\hline Diameter of reactor & 1.5 \\
\hline Height of draft tube & 5.96 \\
\hline Diameter of draft tube & 1.12 \\
\hline
\end{tabular}
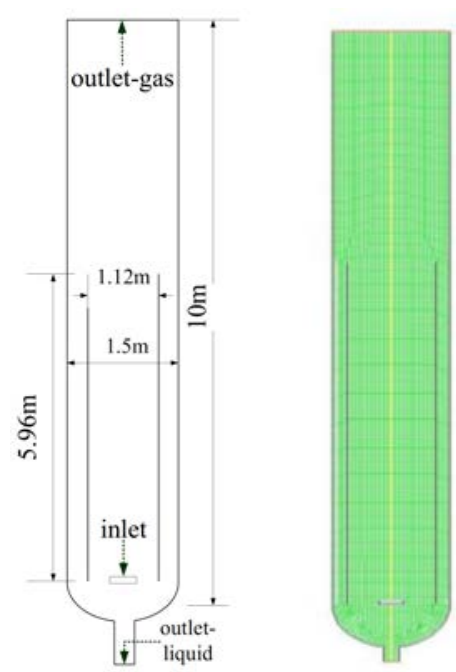

Fig. (6). Size and grid of internal airlift loop reactor model.

\section{RESULTS AND DISCUSSION}

\subsection{Physical Properties and Bubble Size}

\subsubsection{Influence of Gas Density}

In this case, simulations are carried out for different densities of hydrogen at $0.05231,0.5231,1.5231,2.5231$ $\mathrm{kg} / \mathrm{m}^{3}$, besides, the liquid density is $736.9154 \mathrm{~kg} / \mathrm{m}^{3}$ and viscosity is $0.001 \mathrm{~Pa} \cdot \mathrm{s}$. Liquid velocity and gas hold-up at certain height of cross-section $(\mathrm{h}=4500 \mathrm{~mm})$ can be observed in Figs. $(7,8)$, respectively.

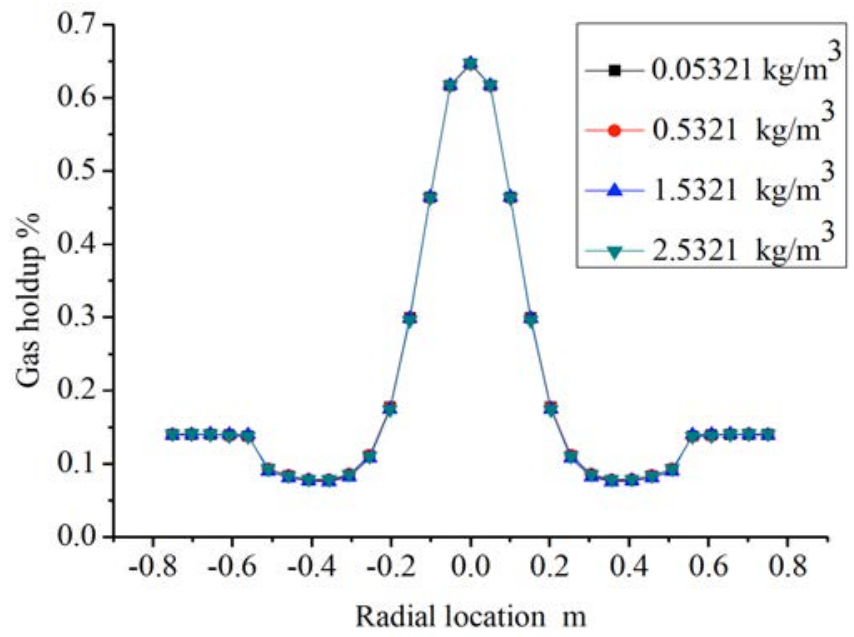

Fig. (7). Gas hold-up under different gas density at certain height of cross-section $(\mathrm{h}=4500 \mathrm{~mm})$. 
As is shown in the figures, liquid circulation velocity and gas hold-up are almost equal under different gas density. So we come to the conclusion that gas density have little effect on flow field and gas hold-up.

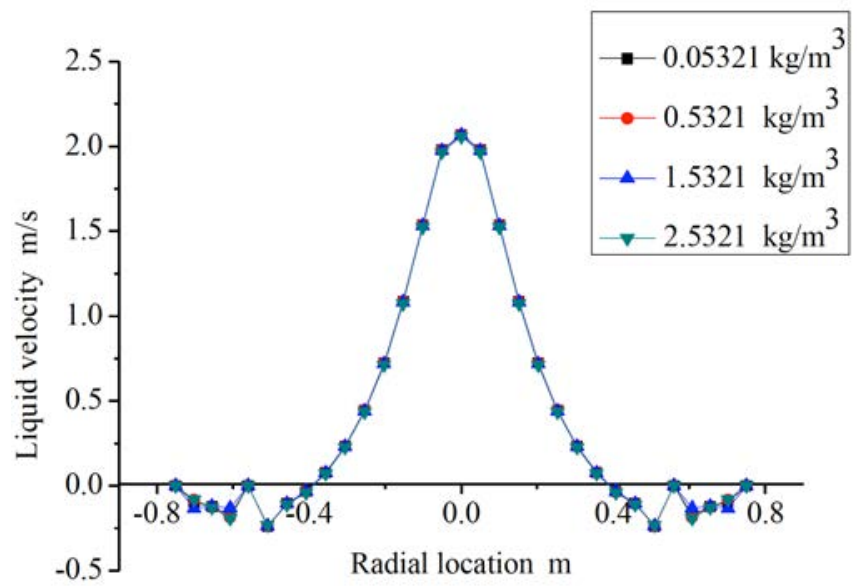

Fig. (8). Liquid velocity under different gas density at certain height of cross-section $(\mathrm{h}=4500 \mathrm{~mm})$.

\subsubsection{Influence of Liquid Viscosity}

The flow field and gas hold-up in the loop reactor are investigated under the conditions of liquid viscosities $0.0087,0.00187,0.00287,0.00387 \mathrm{~kg} / \mathrm{m} \cdot \mathrm{s}$.

As can be seen from Fig. (9), maximum liquid velocity can be obtained when liquid viscosity is $0.00087 \mathrm{~kg} / \mathrm{m} \cdot \mathrm{s}$, and liquid velocity decreases with the increasing of viscosity. As is shown in Fig. (10), maximum gas hold-up appears when liquid viscosity is $0.00387 \mathrm{~kg} / \mathrm{m} \cdot \mathrm{s}$, and liquid velocity increases as the viscosity becomes larger.

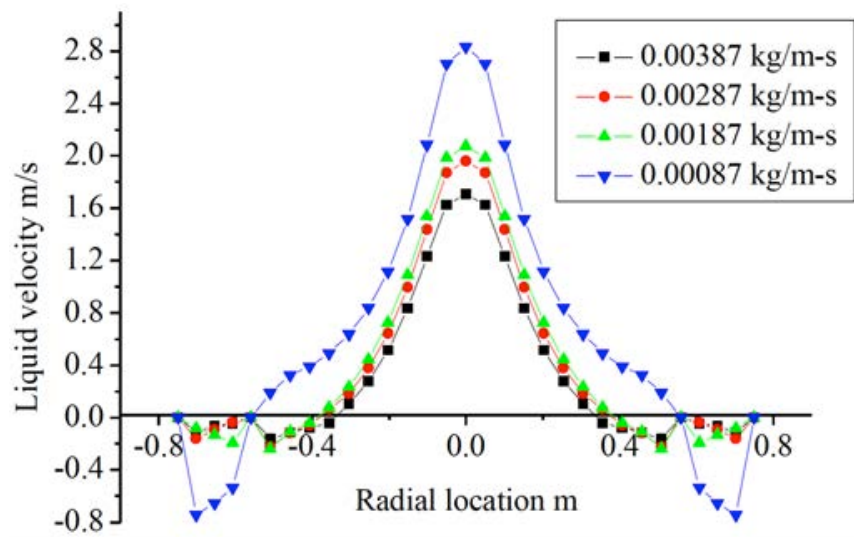

Fig. (9). Liquid velocity under different viscosity at certain height of cross-section $(\mathrm{h}=4500 \mathrm{~mm})$.

\subsubsection{Influence of Bubble Size}

The liquid velocity and gas hold-up under different bubble size 1, 2, 3 and $4 \mathrm{~mm}$ are compared.

The liquid velocity of different bubble size at certain height $(\mathrm{h}=4500 \mathrm{~mm})$ is shown in Fig. (11), from which the minimum circulation velocity is found when bubble size is $1 \mathrm{~mm}$. The gas hold-up of different bubble size at $4500 \mathrm{~mm}$ cross-section is shown in Fig. (12), we notice that gas holdup is maximum when bubble size is $1 \mathrm{~mm}$. Therefore it is quite clear that flow resistance increases with the increasing of gas hold-up in annular space.

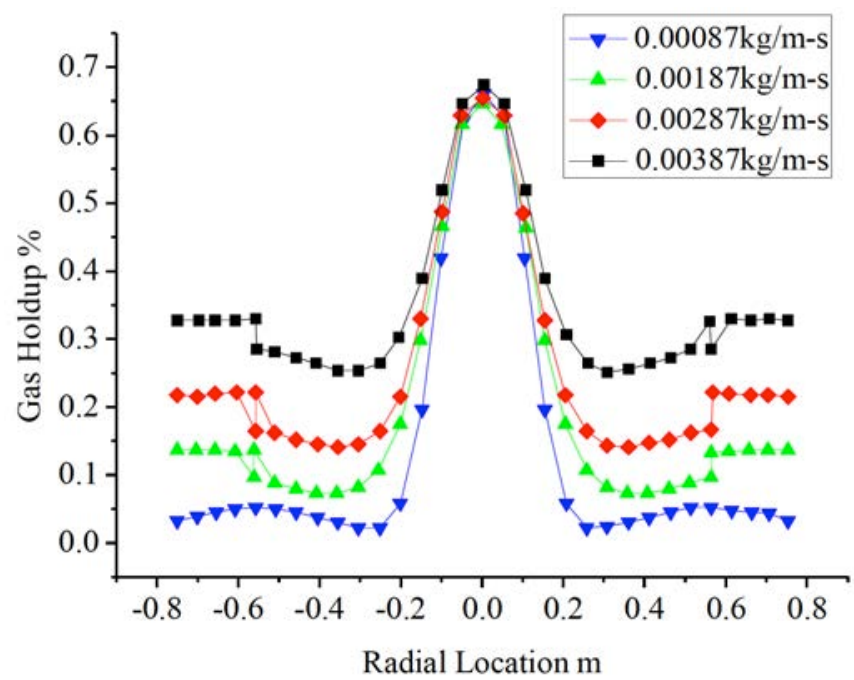

Fig. (10). Gas hold-up under different viscosity at certain height of cross-section $(\mathrm{h}=4500 \mathrm{~mm})$.

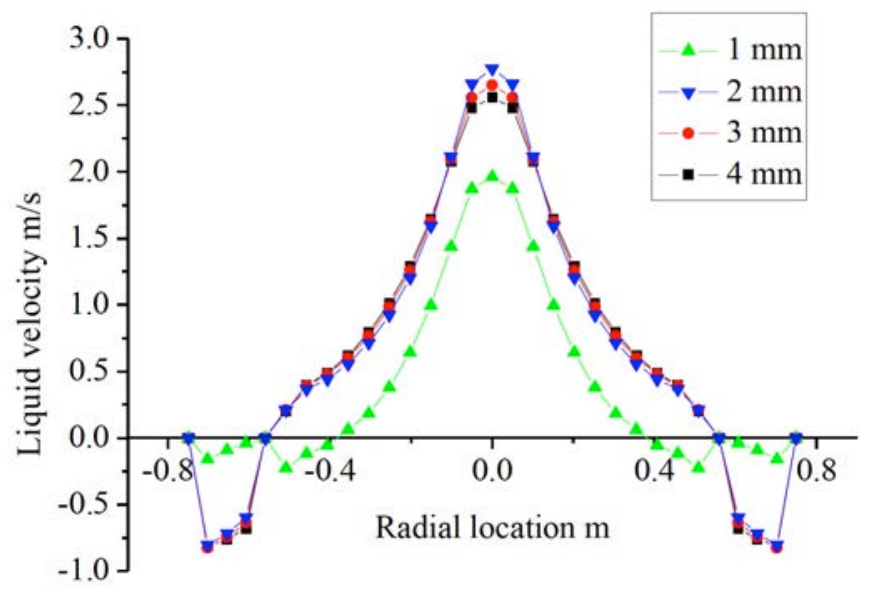

Fig. (11). Liquid velocity under different bubble diameter at certain height of cross-section $(\mathrm{h}=4500 \mathrm{~mm})$.

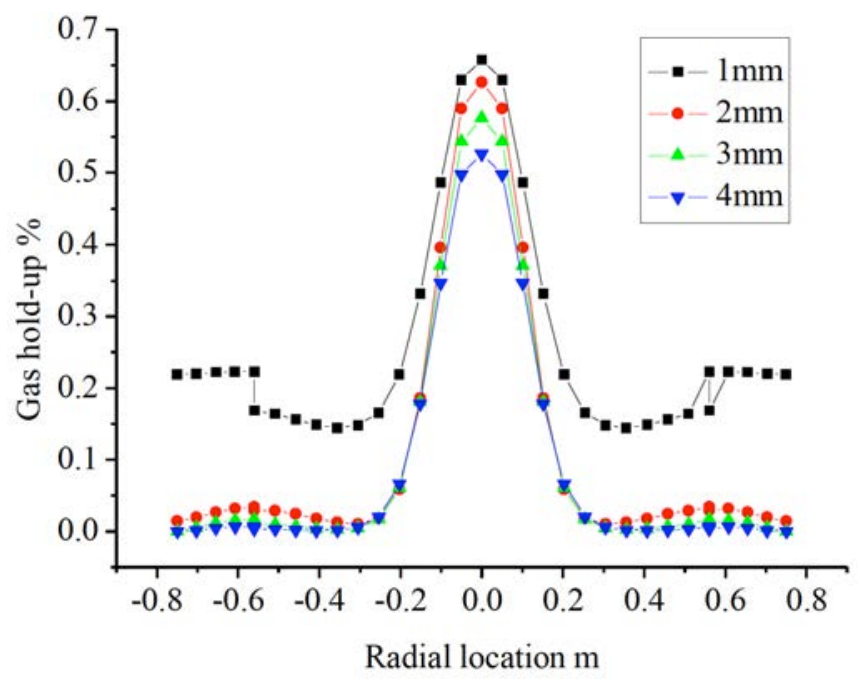

Fig. (12). Gas hold-up under different bubble diameter at certain height of cross-section $(\mathrm{h}=4500 \mathrm{~mm})$. 


\subsection{Influence of Different Structure}

\subsubsection{Different Stage}

The function of the draft tube is to form a well-organized flow field in the reactor. By comparison of the different draft tube with different stage which is designed by Tsinghua University [9], it is found that the structure of the draft tube has a big effect on the flow field. The structure and dimension of the draft tubes are presented in Fig. (13).

Simulation results for the liquid velocities are presented in Fig. (14). The maximum liquid velocity is discovered around the third stage in the three-stage draft tube, while the minimum value appears around the first stage draft tube. And the flow field for the first stage and second stage draft tube is similar. Fig. (15) shows the difference of liquid velocity between the first stage and the second stage in the two-stage draft tube.

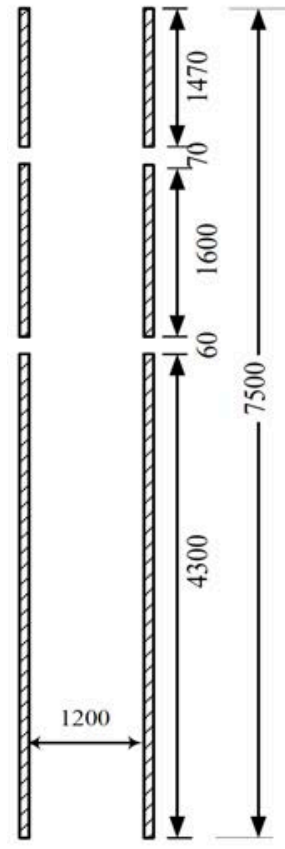

(A)

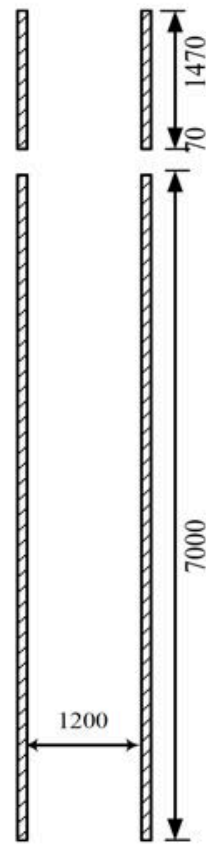

(B)

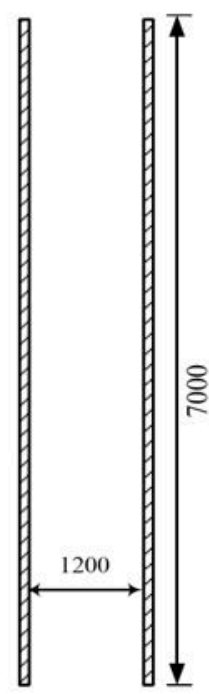

(C)
Fig. (13). Different structure of the draft tube.

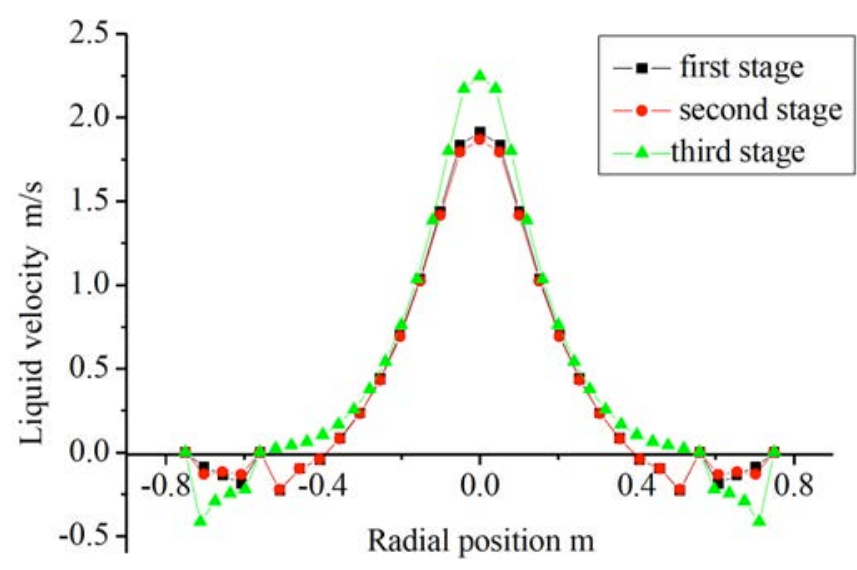

Fig. (14). Liquid velocity under different draft tube position.

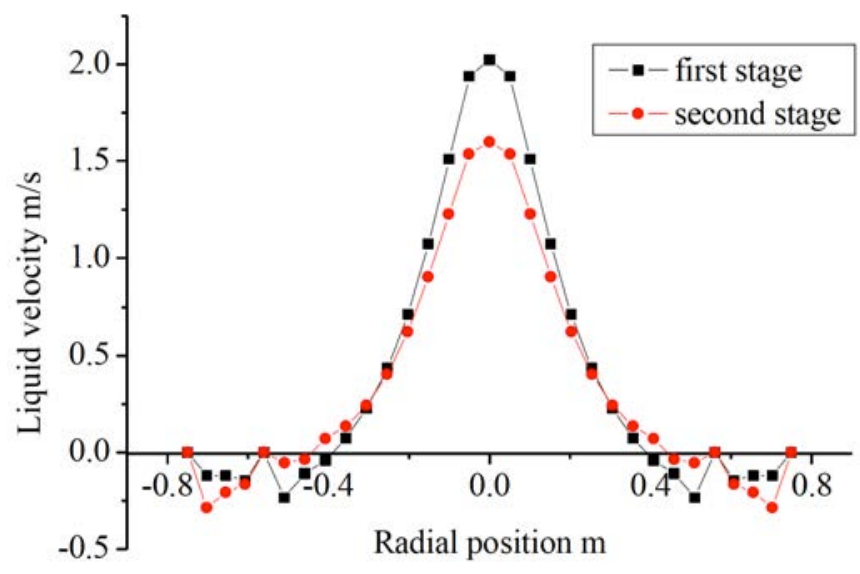

Fig. (15). Liquid velocity under different draft tube position.

\subsubsection{Different Height of the Draft Tube}

Apparently, with higher height of draft tube, the filled height of the liquid will also increase, and the residence time is longer. The liquid velocity for different height of draft tube 5, 5.96, and $6.6 \mathrm{~m}$ are depicted in Fig. (16). The results show little difference of liquid velocity except in the center of the reactor. Obviously, the height of $5.96 \mathrm{~m}$ is improper for its minimum velocity in the center. The velocities under height of $5 \mathrm{~m}$ and $6.6 \mathrm{~m}$ are nearly equal to each other. So the equipment cost should be considered to determine the appropriate height of draft tube. The tube of height $6.6 \mathrm{~m}$ must be more expensive than that of $5 \mathrm{~m}$. Thus the height of $5 \mathrm{~m}$ is optimal among the three studied heights.

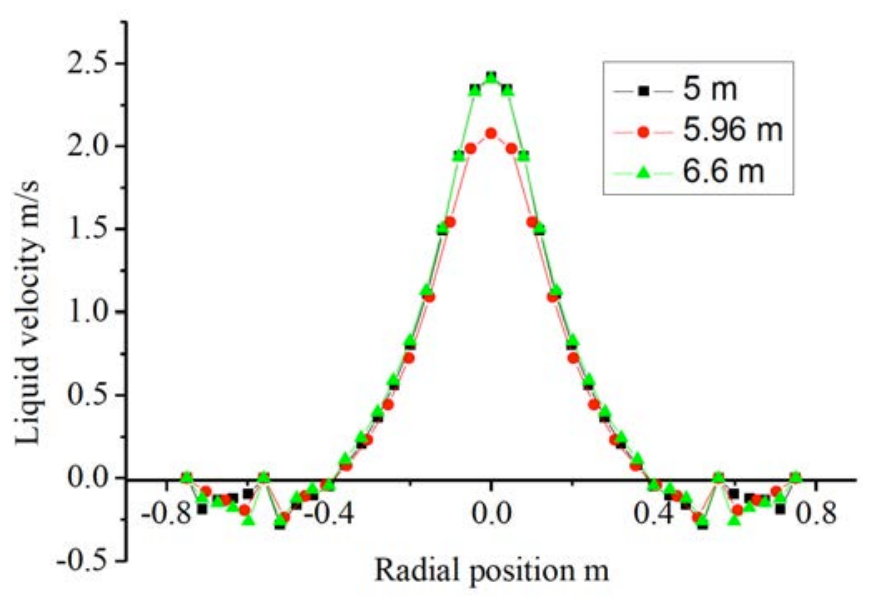

Fig. (16). Liquid velocity under different height of draft tube.

\subsubsection{Different Diameter of the Draft Tube}

Fig. (17) shows liquid velocity under different diameter of draft tube $0.98,1.12,1.2 \mathrm{~m}$. A comparatively uniform flow field can be obtained from the draft tube with the diameter $0.98 \mathrm{~m}$ and $1.12 \mathrm{~m}$, the latter get a greater loading quantity, so draft tube with a diameter $1.12 \mathrm{~m}$ is recommended.

\subsubsection{Different Bottom Structure of Reactor}

Two elements should be taken into consideration when we design the bottom structure of reactor, one is to make 


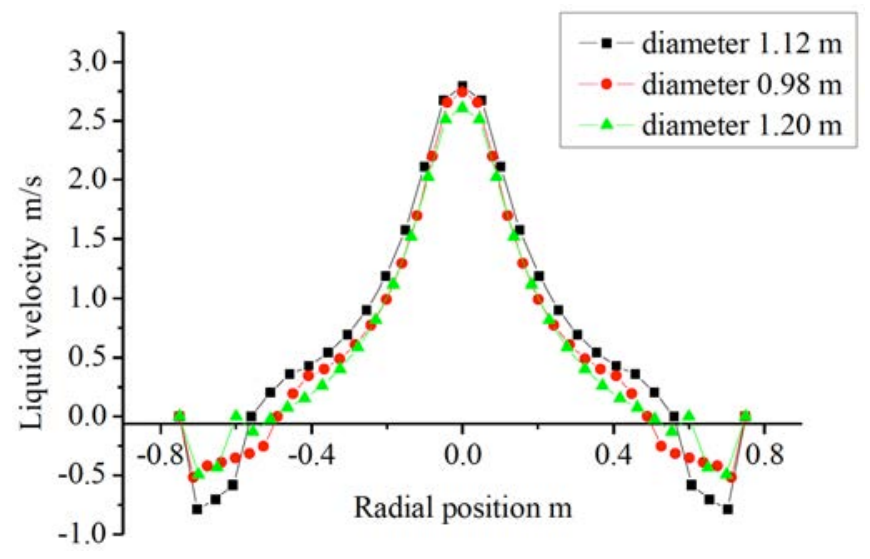

Fig. (17). Liquid velocity under different draft tube diameter.

sure that there are no dead zones at the bottom of the reactor, the other is that the structure should be conducive to the discharge of hard coke. The flow field of different reactor bottom structure (a: oval, b: taper, c: roundness) are presented in Fig. (18). By comparison of the flow field, we notice that the dead zones are inevitable in all the reactors with different structure, but the taper one is more conductive to the discharge of the hard coke for its advantage of certain inclination and large space.
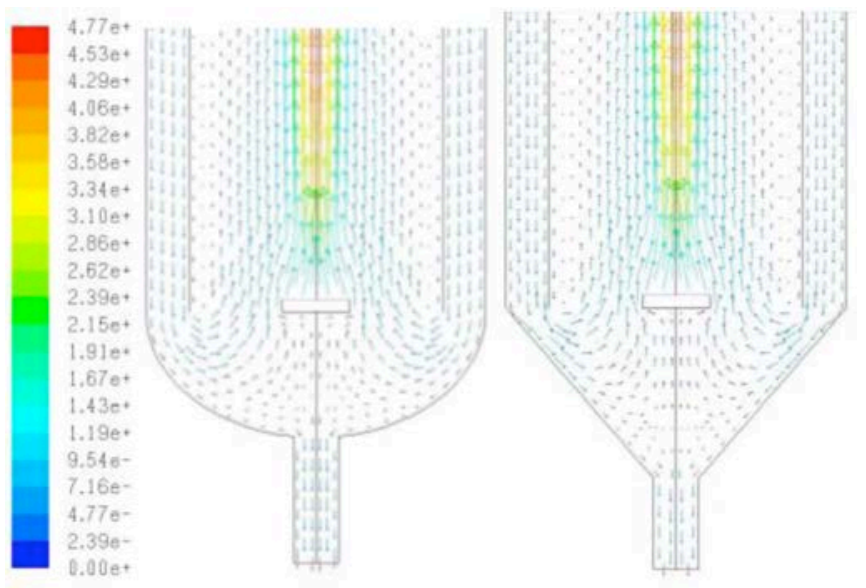

a

b
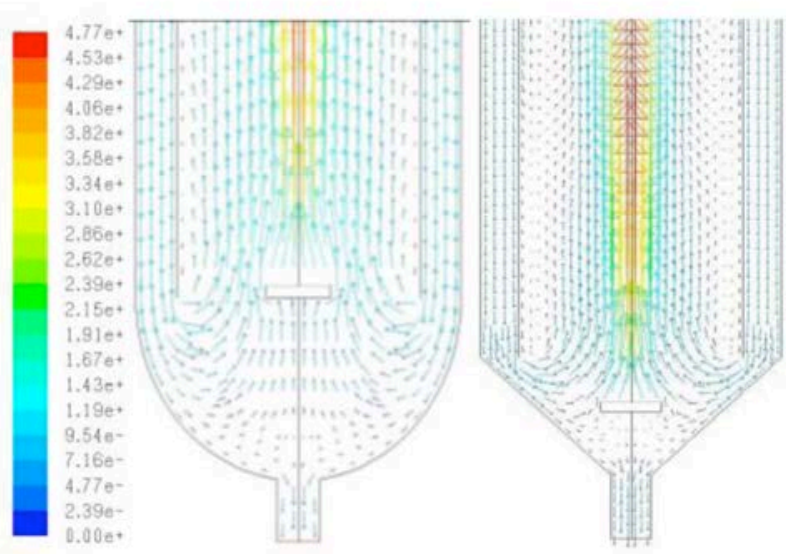

c

d

The height of the distributor is decreased to $300 \mathrm{~mm}$ below the draft tube so that the dead zones are significantly reduced, which is presented in Fig. (18d). The reason is that lower position of the distributor can reduce the flow resistance.

\subsection{Influence of Other Factors}

\subsubsection{Different Filled Height of Liquid}

Liquid circulation velocities for different liquid height under different superficial gas velocity are shown in Fig. (19). As the filled height of liquid increases, the liquid circulation velocity will rise, and the gas hold-up at the bottom will increase accordingly.

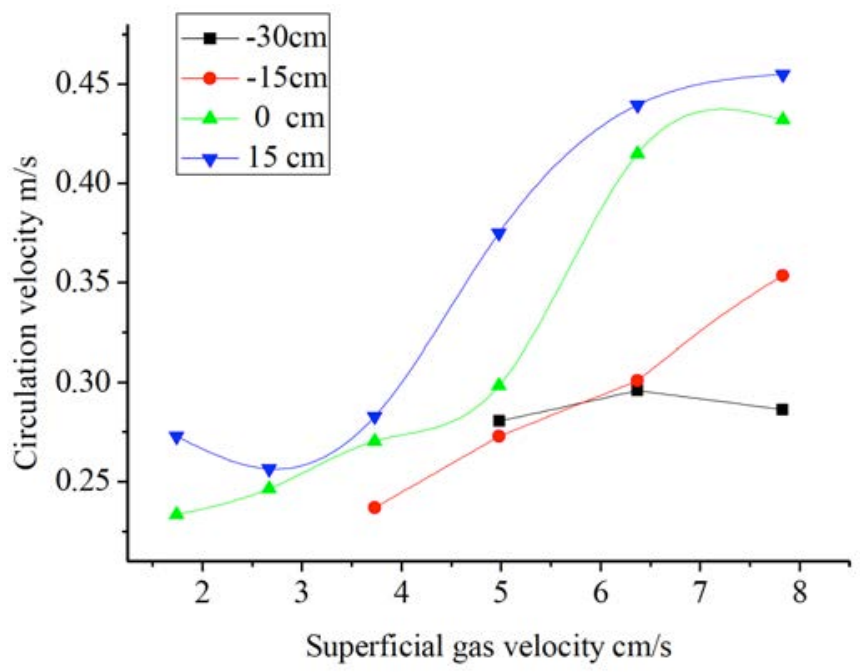

Fig. (19). Liquid circulation velocity versus superficial gas velocity under different filled height.

\subsubsection{Scale-up of the Reactor}

Liquid velocity and gas hold-up in the reactor of different size can be obtained from simulations. The diameter of reactor in the simulation is magnified by a factor of three, four and five. The relevant size is also magnified accordingly. The scaled-up reactor dimensions are summarized in Table 2.

Fig. (20) shows the liquid circulation velocity under different diameter, we notice that there are some irregular flow region at radial position $0.35-0.56 \mathrm{~m}$. This is due to the unreasonable structure of the draft tube and the distribution of the gas distributor. And the irregularity becomes greater as the diameter increases. To prevent this from happening, the smaller diameter of draft tube and optimal position of the gas distributor are both needed.

As is shown in Fig. (20), liquid circulation velocity in downcomer hardly changes after the scale-up of the reactor. However, the unreasonable temperature distribution along the reactor appears because the height of the draft tube correspondingly increases.

The gas hold-up versus radial position in different reactors is shown in Fig. (21). It is found that gas hold-up increases with increasing of the reactor diameter, however, when diameters scale up to five times or more, gas hold-up

Fig. (18). Liquid velocity at different bottom structure. 
Table 2. Scale-up parameters of the reactor.

\begin{tabular}{|c|c|c|c|c|c|}
\hline Height of Reactor/m & Diameter of Reactor/m & Height of Draft Tube/m & Diameter of Draft/m & $\begin{array}{c}\text { Diameter of the Draft Tube/ } \\
\text { Diameter of the Reactor }\end{array}$ \\
\hline \hline 60 & $4.0 \times 2$ & 35.0 & $3.0 \times 2$ & 0.75 & 5 \\
\hline 48 & $3.2 \times 2$ & 28.0 & $2.4 \times 2$ & 0.75 & 0.75 \\
\hline 36 & $2.4 \times 2$ & 21.0 & $1.8 \times 2$ & 0.75 & 3 \\
\hline 12 & $0.8 \times 2$ & 7.0 & $0.6 \times 2$ & & 1 \\
\hline
\end{tabular}

will decrease instead. The reason is that, when the diameter remain unchanged, annular space is too narrow for the entrance of the bubble, and the oversize diameter also weight against the gas hold-up, consequently, additional time is needed for bubble circulation from the middle to annular space. To minimize the loss of bubbles, the distributor which can produce smaller bubble diameter is recommended.

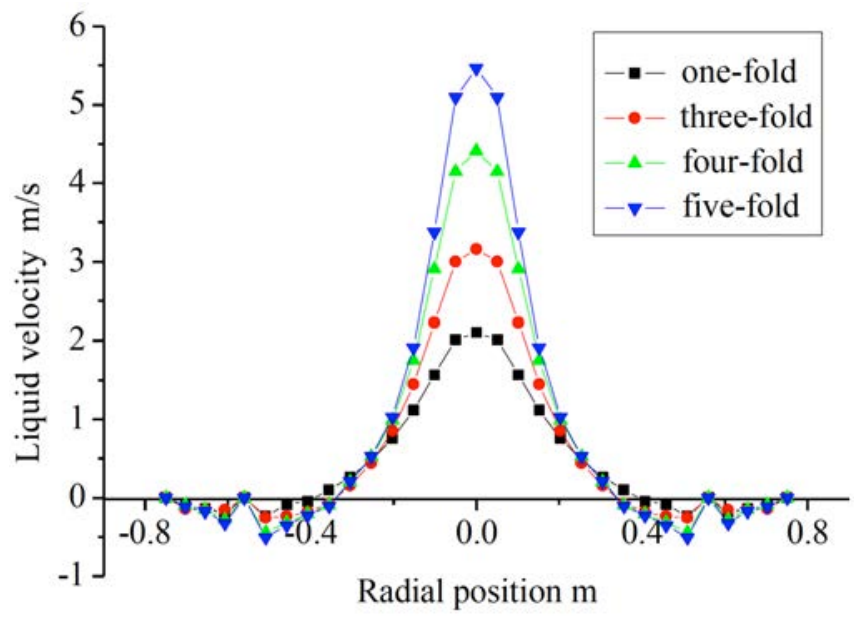

Fig. (20). Liquid velocity distribution versus radial position.

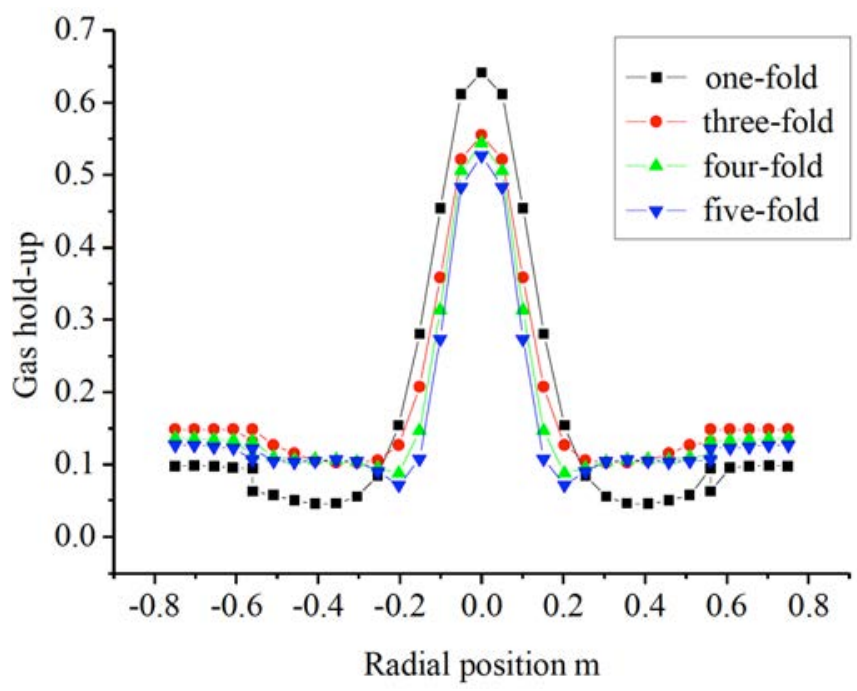

Fig. (21). Gas hold-up distribution versus radial position.

\section{CONCLUSIONS}

This paper provides an analysis of the effect of physical properties, reactor structures and the reactor scale-up on the flow field and gas hold-up. The optimal structure and the operation parameters can be obtained through simulation as well.

The results show that the gas density has little impact while the liquid viscosity has a significant effect on flow field and gas hold-up. The height of draft tube has little influence on the flow field, and height $5 \mathrm{~m}$ is considered to be optimal from the point of equipment cost. Appropriate diameter of tube in the studied reactor should be $1.12 \mathrm{~m}$. The taper bottom is more conductive to the discharge of the hard coke. In view of the magnification of the reactor, the diameters of the draft tube and the choice of distributor are very important.

On the basis of the promising results obtained in this paper we conclude that CFD simulations can be a powerful design and scale-up tool. And it is recommended to consider the gas hold-up, liquid velocity and equipment cost together as a whole to decide the dimensions of the draft tube.

\section{NOMENCLATURE}

$F \quad=\quad$ Body force $\left(\mathrm{N} / \mathrm{m}^{3}\right)$

$g \quad=\quad$ Acceleration due to gravity $\left(\mathrm{m} / \mathrm{s}^{2}\right)$

$k=\quad$ Turbulent kinetic energy $\left(\mathrm{m}^{2} / \mathrm{s}^{2}\right)$

$K=$ Momentum transfer coefficient $\left(\mathrm{kg} / \mathrm{m}^{3} \cdot \mathrm{s}\right)$

$m_{p q}=\quad$ Mass transfer from phase $p$ to $q\left(\mathrm{~kg} / \mathrm{m}^{3} \cdot \mathrm{s}\right)$

$p \quad=\quad$ Pressure shared by all phases $\left(\mathrm{N} / \mathrm{m}^{2}\right)$

$P_{k} \quad=\quad$ The exact production term

$t \quad=\quad$ Time (s)

$u_{q} \quad=\quad$ Velocity of $q$ th phase $(\mathrm{m} / \mathrm{s})$

\section{Greek Letters}

$\begin{array}{lll}\alpha_{q} & = & \text { Volume fraction of phase } q(-) \\ \rho_{q} & = & \text { Density of phase } q\left(\mathrm{~kg} / \mathrm{m}^{3}\right) \\ \varepsilon & = & \text { Turbulence dissipation rate }(-) \\ \mu & = & \text { Dynamic viscosity }(\mathrm{Pa} \cdot \mathrm{s}) \\ \overline{\bar{\tau}} & = & \text { Stress-strain tensor }\left(\mathrm{N} / \mathrm{m}^{2}\right)\end{array}$

\section{Subscripts}

$\begin{array}{lll}p, q & = & \text { Phase number } \\ t & = & \text { Turbulent }\end{array}$




\section{CONFLICT OF INTEREST}

The authors confirm that this article content has no conflict of interest.

\section{ACKNOWLEDGEMENTS}

This work was supported by the National Natural Science Foundation of China (21276279) and the Fundamental Research Funds for the Central Universities (27R1204008A).

\section{REFERENCES}

[1] Liu, Y.; Gao, L.; Wen, L.; Zong, B. Recent advances in heavy oil hydroprocessing technologies. Recent Patents Chem. Eng., 2009, 2, 22-36.

[2] Zhang, S.; Deng, W.; Liu, D.; Que, G. New development of slurrybed heavy oil hydrocracking process. Petrol. Refinery Engineering, 2007, 37(2), 1-6.

[3] Alonso-Pippo, W.; Luengo, C.A.; Fonseca, F.F.; Garzone, P.; Cornacchia, G. Cogeneration and bio-oil production starting from sugarcane biomass residues: barriers, challenges and opportunities. Open Fuels Energy Sci. J., 2009, 2, 34-39.

[4] Motaghi, M.; Ulrich, B.; Subramanian, A. Slurry-phase hydrocracking - possible solution to refining margins. Hydrocarb. Process, 2011, 37-43.

[5] Zhang, S.; Liu, D.; Deng, W.; Que, G. A review of slurry-phase hydrocracking heavy oil technology. Energy Fuel, 2007, 11(6), 3057-3062.

[6] Liu, Y.; Gao, L.; Wen, L.; Zong, B. Development of slurry bed technologies for upgrading heavy oils. Chem. Ind. Eng. Prog., 2010, 29(9), 1589-1596.

[7] Wang, J.; Zhang, Z.; Li, Y.; Jia, L.; Dong, Z.; Li, H. Development of a slurry-bed residue hydroconversion process. Ind. Catal., 2003, 11, 7-13.
[8] Fang, L.; Guo, J.; Wu, X.; Feng, X. The study current status and prospect on slurry bed for residue hydrotreatment. Chemical Intermediate, 2008, 9, 4-10.

[9] Han, L. Thesis, China University of Petroleum, 2009.

[10] Li, F. Thesis, Tsinghua University, 2004.

[11] Rahman, M.A.; Heidrick, T.; Fleck, B.A. Critical review of advanced experimental techniques to measure two-phase gas/liquid flow. Open Fuels Energy Sci. J., 2009, 2, 54-57.

[12] Laborde-Boutet, C.; Larachi, F.; Dromard, N.; Delsart, O.; Schweich, D. CFD simulation of bubble column flows: Investigations on turbulence models in RANS approach. Chem. Eng. Sci., 2009, 64, 4399-4413.

[13] Luo, H.; Al-Dahhan, M.H. Verification and validation of CFD simulations for local flow dynamics in a draft tube airlift bioreactor. Chem. Eng. Sci., 2011, 66, 907-923.

[14] Wang, T.; Wang, J. Numerical simulations of gas-liquid mass transfer in bubble columns with a CFD-PBM coupled model. Chem. Eng. Sci., 2007, 62, 7107-7118.

[15] Simcik, M.; Mota, A.; Ruzicka, M.C.; Vicente, A.; Teixeira, J. CFD simulation and experimental measurement of gas holdup and liquid interstitial velocity in internal loop airlift reactor. Chem. Eng. Sci., 2011, 66, 3268-3279.

[16] Moraveji, M.K.; Sajjadi, B.; Jafarkhani, M.; Davarnejad, R. Experimental investigation and CFD simulation of turbulence effect on hydrodynamic and mass transfer in a packed bed airlift internal loop reactor. Int. Commun. Heat Mass Transfer, 2011, 38, 518-524.

[17] Bannari, R.; Bannari, A.; Selma, B.; Proulx, P. Mass transfer and shear in an airlift bioreactor: Using a mathematical model to improve reactor design and performance. Chem. Eng. Sci., 2011, 66, 2057-2067.

[18] Huang, Q.; Yang, C.; Yu, G.; Mao, Z. CFD simulation of hydrodynamics and mass transfer in an internal airlift loop reactor using a steady twofluid model. Chem. Eng. Sci., 2010, 65, 5527-5536.

[19] Zhang, T.; Wei, C.; Feng, C.; Zhu, J. A novel airlift reactor enhanced by funnel internals and hydrodynamics prediction by the CFD method. Bioresour. Technol., 2012, 104, 600-607.

[20] Wang, X.; Jia, X.; Wen, J. Transient modeling of toluene waste gas biotreatment in a gas-liquid airlift loop reactor. Chem. Eng. J., 2010, 159, 1-10. 